Guirguis B., Shehata M, Duchesne J, Fournier B, Durand B, Rivard P. (2018). The Application of a New Oxidation Mortar Bar Test to Mixtures containing Different Cementing Systems. Const. and Build. Mat. 173, 775-785 


\title{
The Application of a New Oxidation Mortar Bar Test to Mixtures containing Different Cementing Systems
}

\author{
Bassili Guirguis $^{1}$, Medhat H. Shehata ${ }^{1 *}$, Josée Duchesne ${ }^{2}$, Benoit Fournier ${ }^{2}$, Benoit Durand ${ }^{3}$, \\ Patrice Rivard ${ }^{4}$ \\ 1: Department of Civil Engineering, Ryerson University, Toronto, Ontario, Canada \\ 2: Département de géologie et de génie géologique, Université Laval, Québec, QC, G1V 0A6 Canada \\ 3: Material Sciences department, Hydro-Québec Research Institute - IREQ, Varennes, QC, J3X 1S1, Canada \\ 4: Department of Civil Engineering, Université de Sherbrooke, J1K 2R1, Canada
}

\section{Highlights}

- The applicability of oxidation mortar bar test to cementing systems was investigated

- Extended exposure of blends with metakaolin to oxidizing solution causes significant expansion of the paste

- The use of SCMs reduces expansion by reducing the permeation of oxidizing agents into the samples

- The effects of SCMs on reducing oxygen permeation through concrete under field exposure needs to be investigated

\begin{abstract}
The effects of different cementing systems on the expansion of mortars containing iron sulphidebearing aggregate were studied. Using a recently developed oxidation mortar bar test, the results showed that cementing systems containing low-calcium fly ash, metakaolin, slag, high-sulphate resisting Portland cement, or low heat of hydration Portland cement could reduce the expansion by $50 \%$ to $85 \%$. The main suggested mechanisms behind the reduced expansion is the more refined pore structure of samples with SCMs, and the reduced $\mathrm{C}_{3} \mathrm{~A}$ of low heat of hydration Portland cement. The refined pore structure reduces the permeation of the oxidizing solution into the samples. The similarity of this to penetration of oxygen into concrete under field exposure needs to be determined. Soaking the samples for more than 3 hours in the oxidizing agent can produce
\end{abstract}


excessive expansion - not related to oxidation of iron sulphide phases - in samples with cementing blends containing reactive alumina such as metakaolin.

\section{Keywords}

Iron sulphide-bearing aggregate; SEM; Expansion; Metakaolin; Cement Paste

\section{Introduction}

Cases of severe concrete damage due to the oxidation of iron sulphide minerals in some types of concrete aggregate have been identified in different locations around the world. In 1974, Bèrard et al. [1] reported a case of sulphide damage in concrete foundation. The aggregates used in the concrete contained trace amounts of pyrite $\left(\mathrm{FeS}_{2}\right)$ and pyrrhotite $\left(\mathrm{Fe}_{(1-\mathrm{x})} \mathrm{S}\right)$. The same authors indicated that the reaction that caused the expansion and deterioration in concrete was the oxidation of the pyrrhotite. Similarly, a case was found in Penge, South Africa, in 1979 and reported by Oberholster and Kruger [2]. Lugg et al. [3] reported cases of damage in Cornwall and Devon areas in the UK. They attributed the incident to the use of mudrock containing iron sulphide phases during the period from 1900 to 1950. Lugg et al. [3] confirmed that pyrite was the most problematic mineral in the mudrock and that the damage was aggravated by the high relative humidity. Schmidt et al. [4] reported that a higher concentration of oxygen, a higher level of $\mathrm{pH}$, and a smaller size of sulphide mineral particles lead to the faster disintegration of the iron sulphide-bearing aggregates. The mechanism of damage due to oxidation of iron sulphide-bearing aggregates has been reported 
in the literature [5]. In summary, the iron sulphide phases, particularly pyrrhotite and some types of pyrite, are unstable upon exposure to oxygen and humidity. Under this exposure, they oxidize and result in the formation of sulphuric acid and ferrous ions $[5,6]$. Then, the ferrous ions are oxidized to produce rust products, including ferric hydroxide (ferrihydrite or rust) and $\mathrm{FeOOH}$ or ferric oxyhydroxide (goethite) [5]. The sulphuric acid reacts with one of the hydrated Portland cement paste products, i.e. $\mathrm{Ca}(\mathrm{OH})_{2}$, to form gypsum [7], which can then react with the aluminate phases in cement paste forming ettringite [8]. The formation of ettringite in hardened concrete can lead to expansion and disruption [8]. While a small amount of ettringite formation may not cause damage, the formation of an excessive amount within the cement matrix or at the interface between aggregate and paste is known to cause cracks [8].

Besides ettringite, thaumasite is also known as one of the products of sulphate attack, which can have deleterious effects on concrete structures. Thaumasite is a calcium-silicate-sulphatecarbonate-hydrate, which favorably forms at temperatures below $15^{\circ} \mathrm{C}$ (preferably at $0-5^{\circ} \mathrm{C}$ ) [9], although it was also reported to form at temperatures above $20^{\circ} \mathrm{C}[10]$. The source of sulphate could be ettringite, where thaumasite can use it as a nucleation site [11], or the gypsum formed as a result of the oxidation of iron sulphides phases in aggregate [12]. Also, thaumasite was reported to form without the need of ettringite as a nucleation site [11, 12]. Both calcium and silica usually come from calcium silicate hydrates (C-S-H). The source of carbonate might be from the air, which causes the transformation of calcium hydroxide to calcium carbonate, from carbonate fillers used to produce Portland cement, or from the aggregate itself. Thaumasite has received attention [11, 
13] as it consumes C-S-H resulting in strength loss. Other researchers [14] reported that thaumasite could cause expansion, in addition to decomposition of C-S-H.

More than 1000 residential houses and commercial buildings were affected by oxidation of iron sulphide-bearing aggregates in the Trois-Rivières area, Québec, Canada. The deterioration was in the form of pop-outs and map cracking and took place within the first 3 to 5 years after construction $[15,16]$. The aggregate used in this concrete was an igneous rock containing pyrite, and pyrrhotite. Following this case, research was carried out and an oxidation mortar bar test was suggested as part of a protocol to evaluate the potential deleterious character of iron sulphide-bearing aggregates $[17,18]$. This paper adopts the newly-developed mortar bar test [17] to investigate the effects of different cementing blends on the damage due to oxidation of iron sulphide-bearing aggregates. The significance of this research is to find out whether or not a change in cementing materials can reduce the rate of damage due to the oxidation of iron sulphide minerals. Moreover, the research examines the possibility of the conditions of the test to promote reactions other than oxidation of iron sulphide phases in aggregates, and its subsequent sulphate attack, in samples with Supplementary Cementitious Materials (SCMs). 


\section{Materials and experimental program}

\subsection{Cementing materials}

A general use Portland cement (GU-PC), low heat of hydration Portland cement (LH-PC), and high-sulphate resisting Portland cement (HSF-PC) were used in this study. The (HSF-PC) is a blended cement containing about $8 \%$ silica fume. Also, three types of SCMs were used, namely low-calcium fly ash (FA), slag (S) and metakaolin (MK). The SCMs were used at the partial replacement of GU-PC at 25\% for FA (GU-FA), 30\% for S (GU-S), and 10\% for MK (GU-MK). The chemical composition of the cementing materials, along with the calculated phase contents of Portland cements are listed in Table 1. 
Table 1: Chemical composition of the Portland cement and SCMs (mass \%) determined using XRay Fluorescence (XRF).

\begin{tabular}{|c|c|c|c|c|c|c|}
\hline Material Type & GU-PC ${ }^{1}$ & LH-PC $^{2}$ & $\mathrm{HSF}-\mathrm{PC}^{3}$ & $\mathrm{FA}^{4}$ & $S^{5}$ & $\mathrm{MK}^{6}$ \\
\hline LOI $\left(1000^{\circ} \mathrm{C}\right), \%$ & 2.71 & 2.10 & 6.89 & 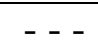 & -- & $-\cdots$ \\
\hline $\mathrm{LOI}\left(750^{\circ} \mathrm{C}\right), \%$ & -- & - - - & -- & 2.78 & 2.90 & 1.82 \\
\hline $\mathrm{SiO}_{2}, \%$ & 19.3 & 20.2 & 23.4 & 47.4 & 37.6 & 63.1 \\
\hline $\mathrm{Al}_{2} \mathrm{O}_{3}, \%$ & 5.22 & 4.00 & 4.22 & 23.9 & 8.23 & 30.7 \\
\hline $\mathrm{Fe}_{2} \mathrm{O}_{3}, \%$ & 2.14 & 3.60 & 2.66 & 17.4 & 0.50 & 1.22 \\
\hline $\mathrm{CaO}, \%$ & 62.0 & 63.8 & 54.9 & 3.67 & 38.1 & 0.36 \\
\hline $\mathrm{MgO}, \%$ & 2.37 & 2.60 & 2.28 & 1.00 & 10.8 & 0.50 \\
\hline $\mathrm{SO}_{3}, \%$ & 3.91 & 2.90 & 3.48 & 0.40 & 2.72 & 0.05 \\
\hline $\mathrm{K}_{2} \mathrm{O}, \%$ & 1.14 & -- & 0.86 & 1.84 & 0.52 & 1.77 \\
\hline $\mathrm{Na}_{2} \mathrm{O}, \%$ & 0.23 & 0.54 & 0.25 & 0.65 & 0.32 & 0.16 \\
\hline $\mathrm{TiO}_{2}, \%$ & 0.27 & -- & 0.23 & 1.23 & 0.53 & 0.68 \\
\hline $\mathrm{SrO}, \%$ & 0.09 & -- & 0.22 & 0.13 & -- & 0.04 \\
\hline $\mathrm{P}_{2} \mathrm{O}_{5}, \%$ & 0.12 & -- & 0.21 & 0.29 & 0.02 & 0.03 \\
\hline $\mathrm{Cl}, \%$ & 0.04 & -- & 0.01 & -- & 0.61 & -- \\
\hline $\mathrm{ZnO}, \%$ & 0.01 & -- & 0.06 & 0.02 & -- & 0.01 \\
\hline $\mathrm{Cr}_{2} \mathrm{O}_{3}, \%$ & 0.01 & -- & 0.01 & 0.03 & -- & 0.01 \\
\hline $\mathrm{Mn}_{2} \mathrm{O}_{3}, \%$ & 0.06 & --- & 0.07 & 0.04 & --- & 0.01 \\
\hline \multicolumn{7}{|c|}{ Phase compositions of GU-PC and LH-PC calculated using Bogue's equations } \\
\hline $\mathrm{C}_{3} \mathrm{~S}(\%)$ & 67 & 61 & & & & \\
\hline $\mathrm{C}_{2} \mathrm{~S}(\%)$ & 5 & 11 & & & & \\
\hline $\mathrm{C}_{3} \mathrm{~A}(\%)$ & 10 & 4 & & & & \\
\hline $\mathrm{C}_{4} \mathrm{AF}(\%)$ & 6 & 11 & & & & \\
\hline \multicolumn{7}{|c|}{$\begin{array}{l}{ }^{1} \text { GU-PC: General Use Portland cement } \\
{ }^{2} \text { LH-PC: Low heat of hydration (or low } \mathrm{C}_{3} \mathrm{~A} \text { ) Portland cement } \\
{ }^{3} \text { HSF-PC: High Sulphate Resisting Portland cement, GU-PC blended with } 8 \% \text { silica fume } \\
{ }^{4} \text { FA: Fly ash (low Calcium) } \\
{ }^{5} \text { S: Slag } \\
{ }^{6} \text { MK: Metakaolin }\end{array}$} \\
\hline
\end{tabular}

The X-Ray Diffraction (XRD) patterns and phase identification of the fly ash, metakaolin, and slag samples are shown in Fig. 1. 

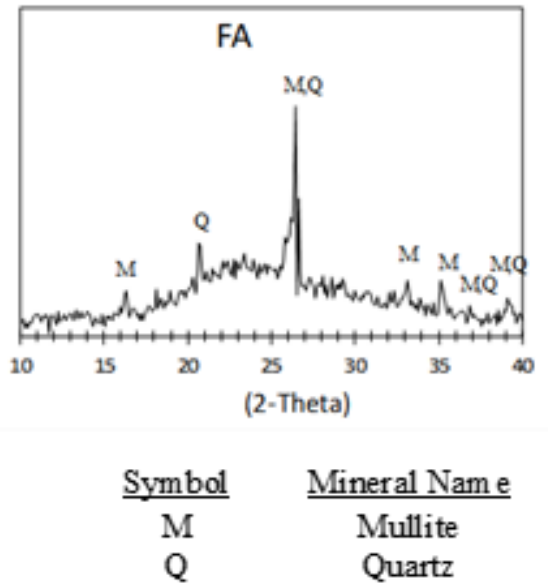
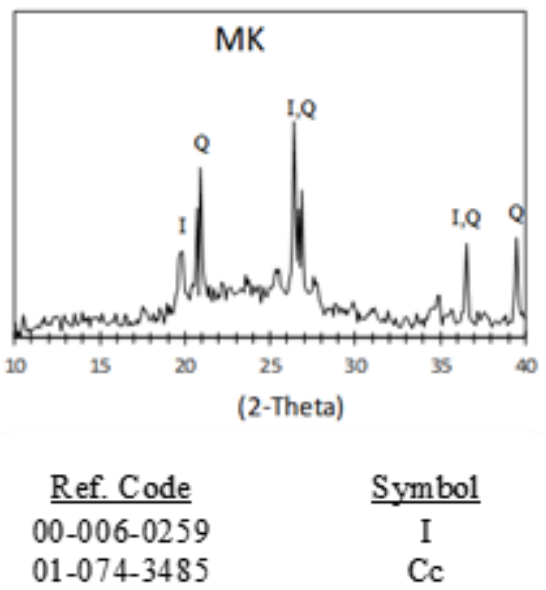

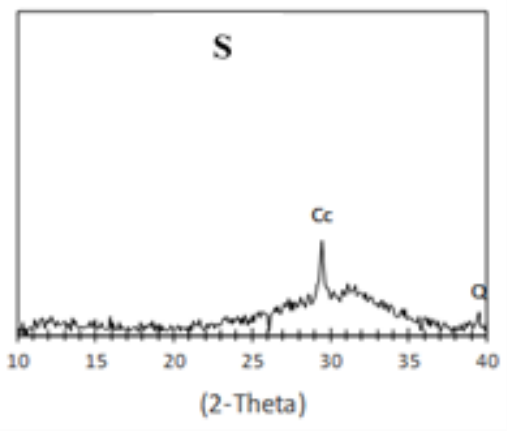

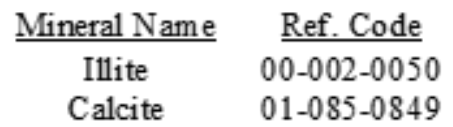

Fig. 1. XRD patterns and pattern list of raw fly ash (FA), metakaolin (MK), and slag (S).

\subsection{Aggregates}

Three different coarse aggregates with different sulphur contents were used in this study, as follows:

(1) MAS: a sulphide-bearing aggregate from Québec, containing pyrrhotite, pyrite, chalcopyrite, and pentlandite. The average sulphide phases comprise about $1 \%$ of the aggregate with a total sulphur content of $0.73 \%-1.28 \%$ [17].

(2) C1: a crushed quarried dolostone from the Amabel Formation in the Hamilton-Burlington area, Ontario, Canada. The main component is calcium magnesium carbonate $\mathrm{CaMg}\left(\mathrm{CO}_{3}\right)_{2}$. In some areas, the formation may contain vugs (open spaces), and it is possible to find (rarely, though) sulphide minerals especially in these open spaces. However, the sample used in this study has negligible or no sulphide minerals as deduced from its very low total sulphur content of $0.007 \%$. The Amabel Formation has an exceptional history of excellent 
field performance as high-quality concrete aggregate in the province of Ontario, Canada with no reported performance issues.

(3) P: an anorthositic rock from Québec, Canada with almost zero sulphide minerals [17].

\subsection{Testing program}

\subsubsection{Penetration of solution at different times of soaking}

To understand the factors that might lead to different expansions when different soaking periods are adopted, the mass gain and penetration of the solution into the mortar bars at different soaking periods were monitored. In this investigation, mortar bar samples were cured for 3 days in a standard curing room at $\mathrm{RH}>95 \%$ and room temperature of $23^{\circ} \mathrm{C}$. Then, the samples were moved from the curing room and exposed to one full cycle of soaking/heating ( 3 hours of soaking in sodium hypochlorite solution following by 3 days in the oven at $\left.80^{\circ} \mathrm{C} / 80 \% \mathrm{RH}\right)$. After the heating period, samples were taken out from the oven and allowed to cool down for half an hour at $23^{\circ} \mathrm{C}$. After that, the mass of the samples was taken and considered as the initial mass $\left(\mathrm{W}_{\mathrm{o}}\right)$. The samples were soaked for 30 hours in the oxidizing solution, and the mass gain of the samples was calculated every 1 hour.

The same test was repeated using $20 \% \mathrm{CaCl}_{2}$ solution instead of the oxidizing solution to allow the detection of the depth of penetration of the solution. This was carried out by breaking a part of the bars at different time intervals - 3, 6, and 24 hours - and spraying the fresh cross-section 
with $0.10 \mathrm{M}$ silver nitrate solution. The part of the cross section with high chloride concentration is manifested by changing the color to silver.

\subsubsection{Oxidation Mortar Bars Test}

The expansion test used in this paper is the mortar bar test described in Rodrigues et al. $[17,18]$. In this test, mortar bar samples are exposed to cycles that promote sulphide oxidation for 13 weeks, followed by another period of 13 weeks under conditions that promote sulphate attack, mainly thaumasite formation. In this paper, the test is further used to study the effect of SCMs on expansion. The mortar bar samples have standard dimensions of $25 \mathrm{~mm}$ x $25 \mathrm{~mm} \times 285 \mathrm{~mm}$. The aggregates were prepared using the same process described in the accelerated mortar bar test for alkali-silica reaction [19]. Almost the same exposure conditions and procedures employed in Rodrigues et al. $[17,18]$ were applied to this research. In addition, samples were tested using longer soaking periods in the oxidizing solution as it will be explained in the following paragraphs.

The mix proportion was 1 part of PC or cementing materials to 3 parts of aggregates at a water-tocement or cementing material ratio (w/c) of 0.65 . After casting, curing for 24 hours in their molds at $23^{\circ} \mathrm{C}$, and demolding, samples were cured for 3 days in a standard curing room at a relative

humidity $(\mathrm{RH})>95 \%$ and room temperature of $23^{\circ} \mathrm{C}$. Samples were then moved from the curing room and soaked immediately for 3 hours in $6 \%$ sodium hypochlorite solution used as an oxidizing solution. After that, the samples were exposed to a temperature of $80^{\circ} \mathrm{C}$ and a $\mathrm{RH}$ of $80 \%$ for 3 days. The relative humidity was achieved by storing the samples over a supersaturated solution of 
$\mathrm{NaCl}$. After the heating period, the samples were taken from the oven and allowed to cool down for half an hour at room temperature before being soaked again for 3 hours in the oxidizing solution. This complete soaking/heating cycle was repeated twice a week; the length change measurements were taken only once per week following the 3 hours of soaking while the mortar bars were in a saturated surface dry condition. At the end of the first 13 weeks, the samples were tested for another 13 weeks under the same soaking period in $6 \%$ sodium hypochlorite solution but with the heating period replaced by storing the samples in a refrigerator at $5^{\circ} \mathrm{C}$ above water $(100 \% \mathrm{RH})$. The test was carried out for a total of 26 weeks. Each mortar bar sample was made up of a minimum of 3 specimens cast from the same mixture.

Samples of the same mixtures were tested another time using the same testing regime, except that a longer soaking period of 24 hours instead of 3 hours was adopted. To maintain 2 cycles per week, the heating period in the first 13 weeks was of 2 days at $80^{\circ} \mathrm{C} / 80 \% \mathrm{RH}$ (instead of 3 days in case of testing with a soaking period of 3 hours). Similarly, the storage period at $5^{\circ} \mathrm{C} / 100 \% \mathrm{RH}$ in the second 13 weeks was of two days. This longer soaking duration was carried out to examine if the SCM has an effect on reducing the damaging expansion beyond that of reducing the penetration of the oxidizing solution, which was thought to be the main factor when using a soaking period of 3 hours.

In addition to testing samples with SCMs, the effect of w/c was examined by testing two mortar bars at w/c of 0.45 and 0.65 containing MAS aggregate. The intent of this was to examine/confirm 
the effect of permeability on the results of the test. This test was carried out using a soaking period of 3 hours.

\subsubsection{Microstructure characterization}

Samples from mortar bars were cut, dried under vacuum, impregnated with epoxy, and molded as a polished section for Scanning Electron Microscopy (SEM) and Energy Dispersive Spectroscopy (EDS) examination. The samples were polished with a diamond grade of $0.3 \mu \mathrm{m}$. The polished specimens were sputtered with carbon using Edwards Vacuum Coating System Model \# 306A. Polished sections were studied in a JEOL JSM6380 LV (SEM) operated at $20 \mathrm{kV}$ in backscattered electron imaging mode (BSE). The same polishing, carbon coating, and SEM examination procedures were applied to paste samples tested under SEM.

\subsubsection{Paste study}

Paste samples were prepared using GU-PC, GU-FA, and GU-MK. This study aimed at investigating the effects of exposure conditions of the adopted mortar bars test, mainly of the second 13 weeks. The conditions of the second 13 weeks of testing were chosen as some mortar bar samples, particularly the sample containing MK, showed severe expansion only in the second 13 weeks of the test, as will be shown in the results section. The samples were prepared at a w/c of 0.50 as the 0.65 value used in the mortar bar would have produced a very flowable paste that would have suffered bleeding. The paste samples were mixed in a high shear blender for 3 minutes 
of mixing, followed by 2 minutes of rest, then 2 minutes of mixing followed by 2 minutes of rest, and, finally, 1 minute of mixing. This results in a total time of mixing and rest periods of 10 minutes. The paste was poured in plastic cylinders of $50 \mathrm{~mm}$ diameter by $100 \mathrm{~mm}$ height and left to cure at $\mathrm{RH}>95 \%$ and $23^{\circ} \mathrm{C}$ for 3 days.

After the curing period, samples were crushed to pieces passing sieve $9.50 \mathrm{~mm}$ and retained on sieve $4.75 \mathrm{~mm}$. Then, the small pieces were exposed to the same conditions as the second 13 weeks of the mortar bars test method, with a soaking period of 1 day. In other words, the samples were soaked in $6 \%$ sodium hypochlorite solution for 1 day followed by storing in a refrigerator at $5^{\circ} \mathrm{C}$ and $100 \%$ RH (above water) for 2 days. These cycles were repeated twice per week. After 6 weeks, samples were taken out, dried using the solvent replacement method by exposing the samples to alcohol for 3 days, followed by drying in a desiccator at $40^{\circ} \mathrm{C}$ for 1 week.

\subsubsection{Microstructure study}

The samples were prepared for SEM-EDS analysis by impregnating them in epoxy, followed by preparing polished sections.

\subsubsection{Thermal Analysis}

The Differential Thermal Analysis (DTA) was carried out on paste samples containing GU-PC; GU-FA and GU-MK using a Mettler Toledo DSC1 using a heating rate of $10^{\circ} \mathrm{C} / \mathrm{min}$ from $30^{\circ} \mathrm{C}$ to 
$700^{\circ} \mathrm{C}$ under grade 5.0 nitrogen. For thermal analysis, the samples were ground to pass sieve 80 $\mu \mathrm{m}$ and stored in a humidity and carbon dioxide-free environment until testing.

\subsubsection{X-Ray Diffraction}

The XRD was carried out on the same paste samples tested using thermal analysis. The prepared sample was tested in X-ray diffractometer. The internal wavelengths used from anode material of Copper $(\mathrm{Cu})$ and the generator settings of $40 \mathrm{~mA}$ and $45 \mathrm{kV}$ were utilized in this study. For XRD, the samples were ground to pass sieve $80 \mu \mathrm{m}$ and stored in a humidity and carbon dioxide-free environment until testing.

\section{Results and Analysis}

\subsection{Penetration of solution at different times of soaking}

The mass gain versus soaking time for mortar bars with different cementing blends soaked in oxidizing solution is shown in Fig. 2. Only aggregate $\mathrm{P}$ is used here as the intent of the test is to examine the permeability of mortar bars to the testing solution. Hence, aggregate type is unlikely to have an effect, as long as the gradation is the same. 


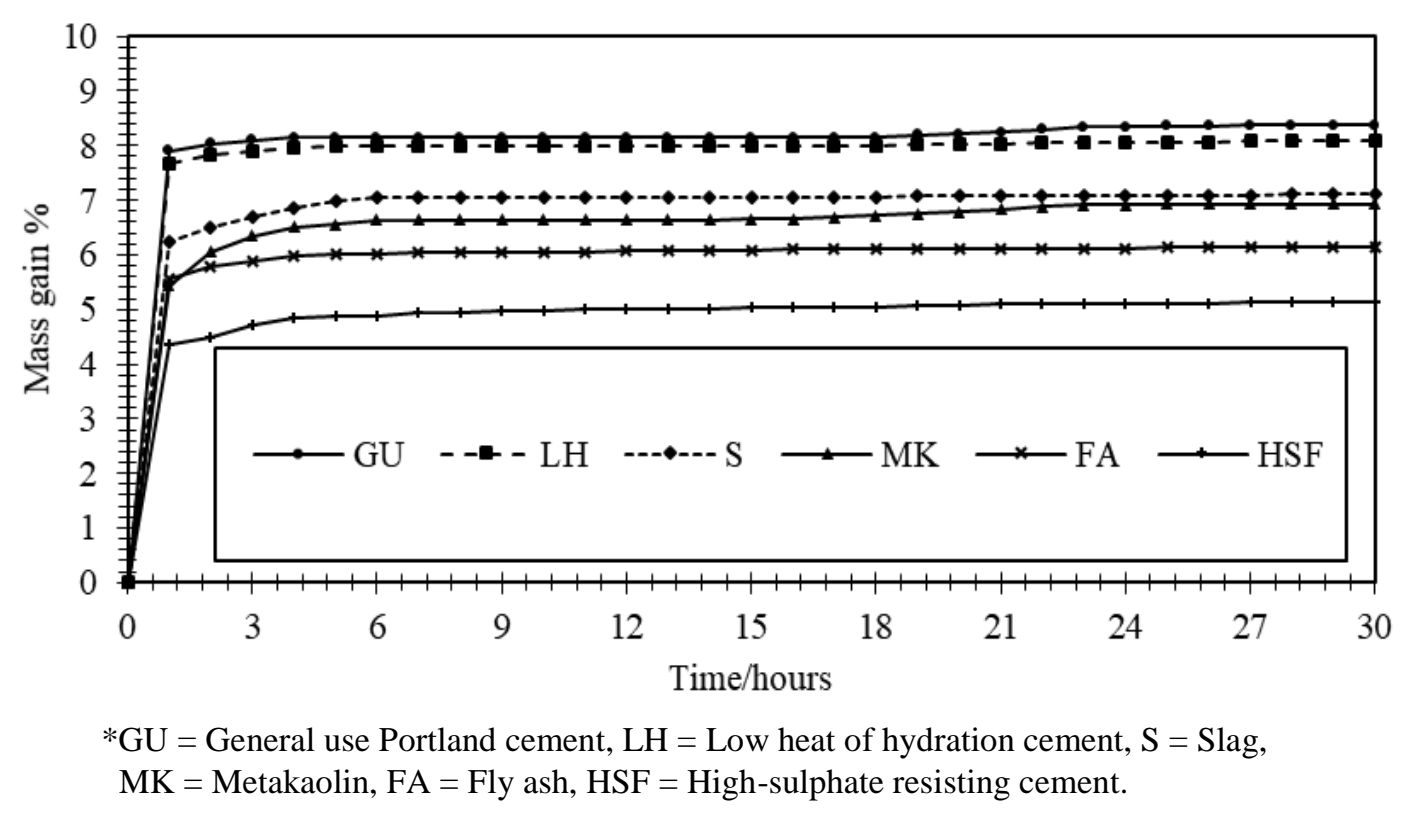

Fig. 2. Mass gain of mortar bar samples made with $P$ aggregate soaked in $6 \%$ sodium hypochlorite solution up to 30 hours.

Most of the mass gain was achieved within the first 3 hours for all samples. The samples tested in $\mathrm{CaCl}_{2}$ solution showed identical curves. However, the concentration of chloride ions within the samples changes with time as illustrated in Fig. 3, in particular for samples with SCMs. This occurs without a significant change in mass of the bars. This finding can be explained based on the conditioning of the samples. Initially, the bars were cured for 3 days in a curing room with RH above $95 \%$. By the end of the 3 days, the sample condition is expected to be close to saturation with water or pore fluid (samples were not yet exposed to external solution). After the 3 days, the bars were maintained at $80 \% \mathrm{RH}$ and $80^{\circ} \mathrm{C}$. This did not permit drying of the samples; rather, it allowed maintaining the $\mathrm{RH}$ at $80 \%$ or above within the sample. Following this, the samples were placed in the soaking solution, while being in partially water-saturated condition. Hence, the mass gain represents how much soaking solution was able to penetrate the samples. The increase in ion 
concentration, without associated mass gain, is likely due to ion diffusion within the sample while the sample is saturated. Another possible explanation is that the cores of samples with SCMs remains at relative humidity higher than $80 \%$ or close to saturation while in the oven due to more refined pore structure of the samples. When placed in solution, the solution penetrates the outer part of the sample cross section, and the ions continue to diffuse within the water-saturated cores of the samples. The implication of this on the observed expansion will be discussed in section

\subsection{1.}

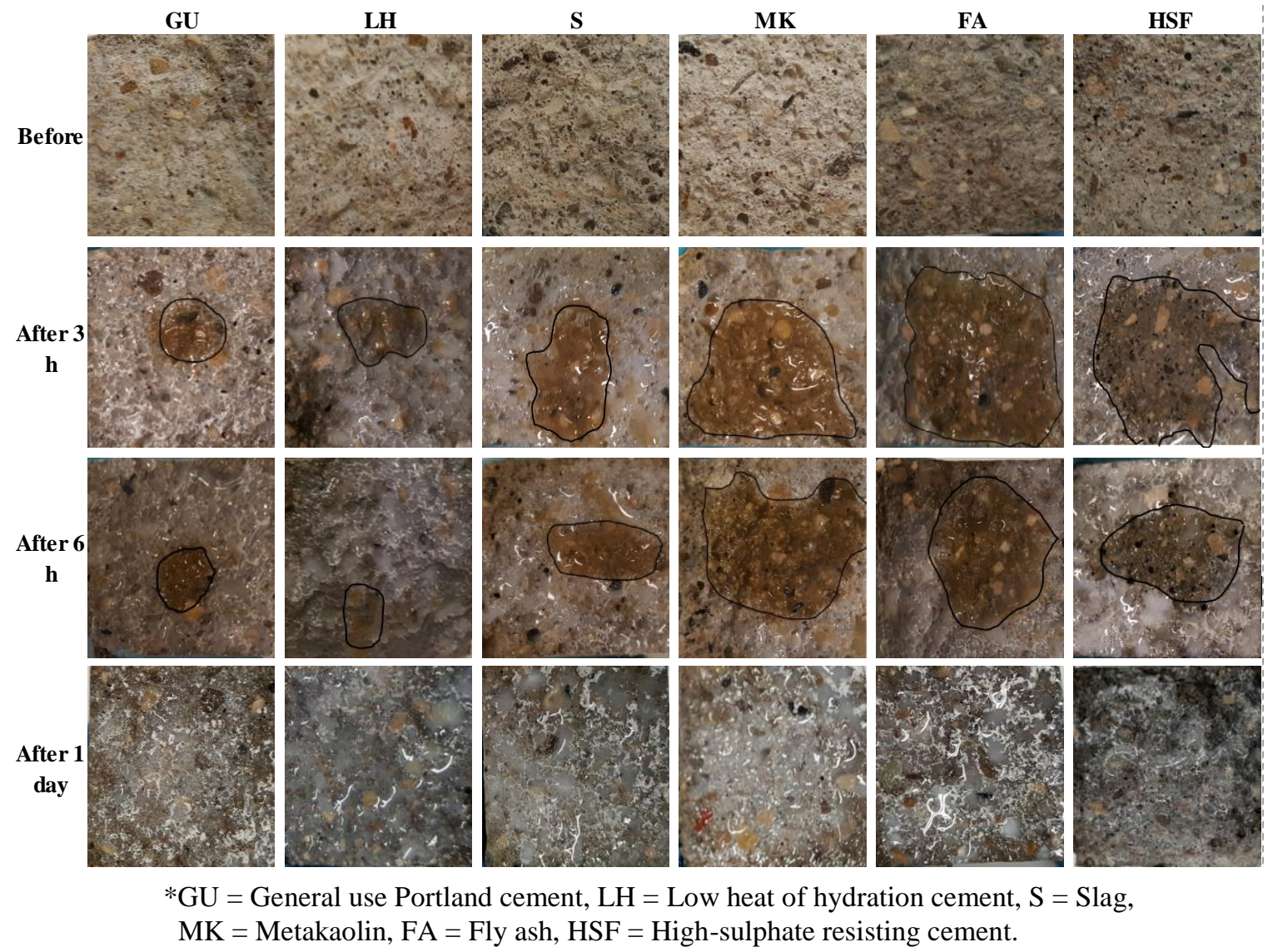

Fig. 3. Migration of chloride ions into the samples made with $\mathrm{P}$ aggregate after different times of exposure. 


\subsection{Oxidation Mortar Bars Test}

\subsubsection{Expansion testing using a soaking period of 3 hours}

The expansion of mortar bars incorporating aggregates $\mathrm{C} 1$, MAS, and $\mathrm{P}$ is shown in Fig. 4a. which provides a baseline of expansions of these aggregates when used without SCMs. The expansion curves of these samples show high expansion in bars with MAS, and limited expansion in bars with the two non-sulphide-bearing aggregates $\mathrm{C} 1$ and P. Fig. $4 \mathrm{~b}$ through $4 \mathrm{f}$ illustrate the expansion of mortar bars with the three aggregates (MAS, C1, and P) when tested with the following cementing blends: GU-PC, LH-PC, GU-S, GU-FA, GU-MK, and the HSF-PC. The LH-PC reduced the expansion compared to samples with only GU-PC, as shown in Fig. 4b. As for SCMs, all types and replacement levels reduced the expansion compared to the GU-PC mix; however, the degree by which each of the SCMs reduced the expansion varied from one SCM to another, with HSF-PC being the most efficient, GU-S (30\% replacement level) being the least effective, while GU-FA (25\% replacement level) was somewhere in the middle. The reduction in expansion was in the range of $50 \%$ to $85 \%$. The samples with GU-S showed lower expansion than samples with GU-PC but higher than samples with other SCMs. This is in line with the results of the salt migration test illustrated in Fig. 3. The sample with GU-S has more migration of salt at 3 hours, representing more migration of oxidizing solution, within the cross-section of the samples compared to samples with other SCMs, but less migration compared to the sample with only GUPC. 

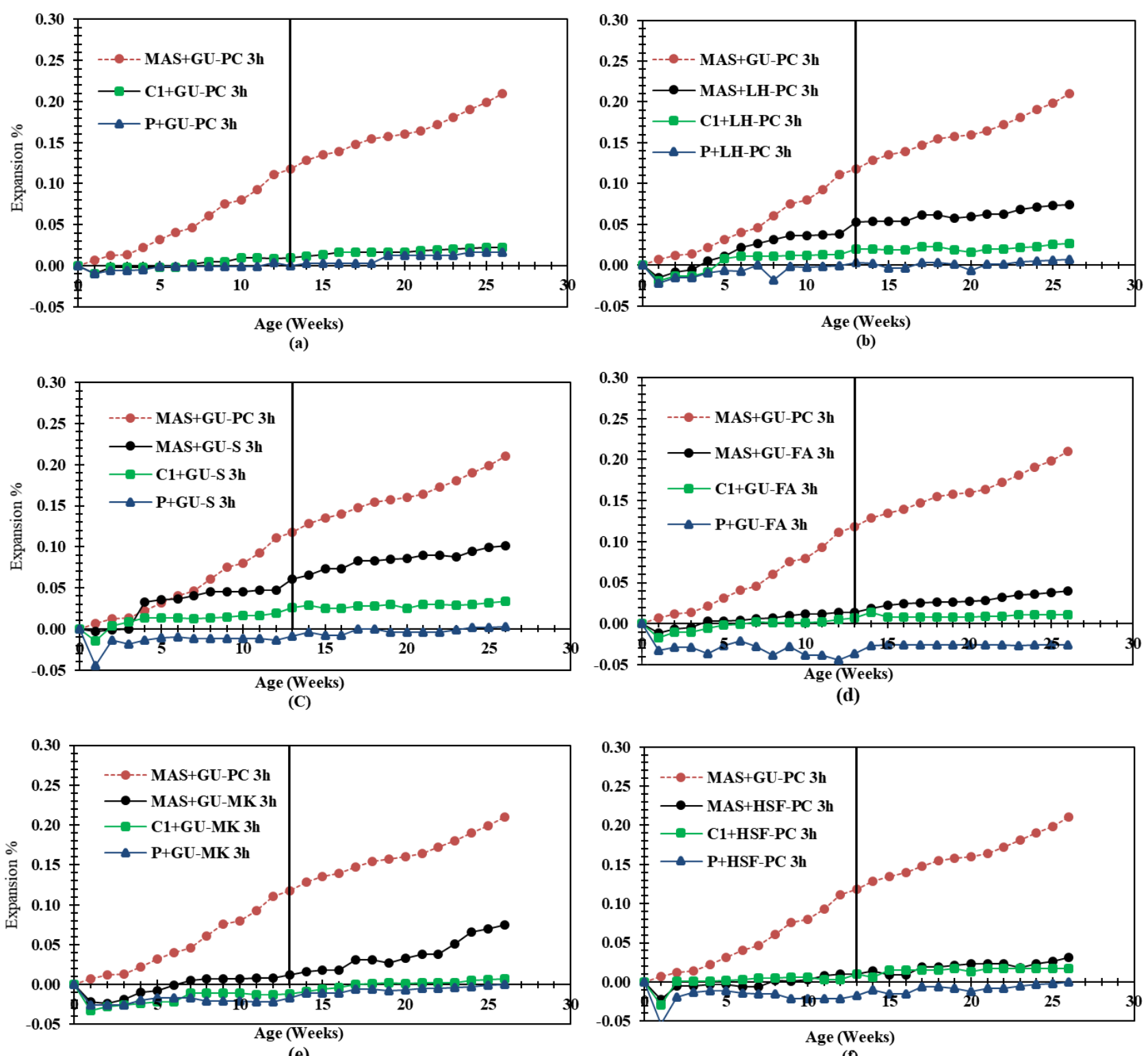

(e)

Fig. 4. Expansions of mortar bars containing $P, M A S$ and $C 1$ aggregates cast with (a) GU-PC, (b) LH-PC, (c) GU-S, (d) GU-FA, (e) GU-MK, and (f) HSF-PC; samples were soaked for 3 hours in $6 \% \mathrm{NaClO}$ solution. Vertical line represents moving the samples from $80^{\circ} \mathrm{C}$ to $5^{\circ} \mathrm{C}$.

While the focus of this paper is to investigate the effect of SCMs on expansion, it was of interest to examine the effect of w/c on the expansion of samples without SCMs. The expansion of two samples made with MAS aggregate prepared using GU-PC at w/c of 0.65 and 0.45 and tested using 
a soaking period of 3 hours are shown in Fig. 5. The samples with w/c ratio of 0.45 showed much lower expansion. The results demonstrate that the refinement of the pore structure of the samples, achieved through using a lower w/c, results in lower expansion.

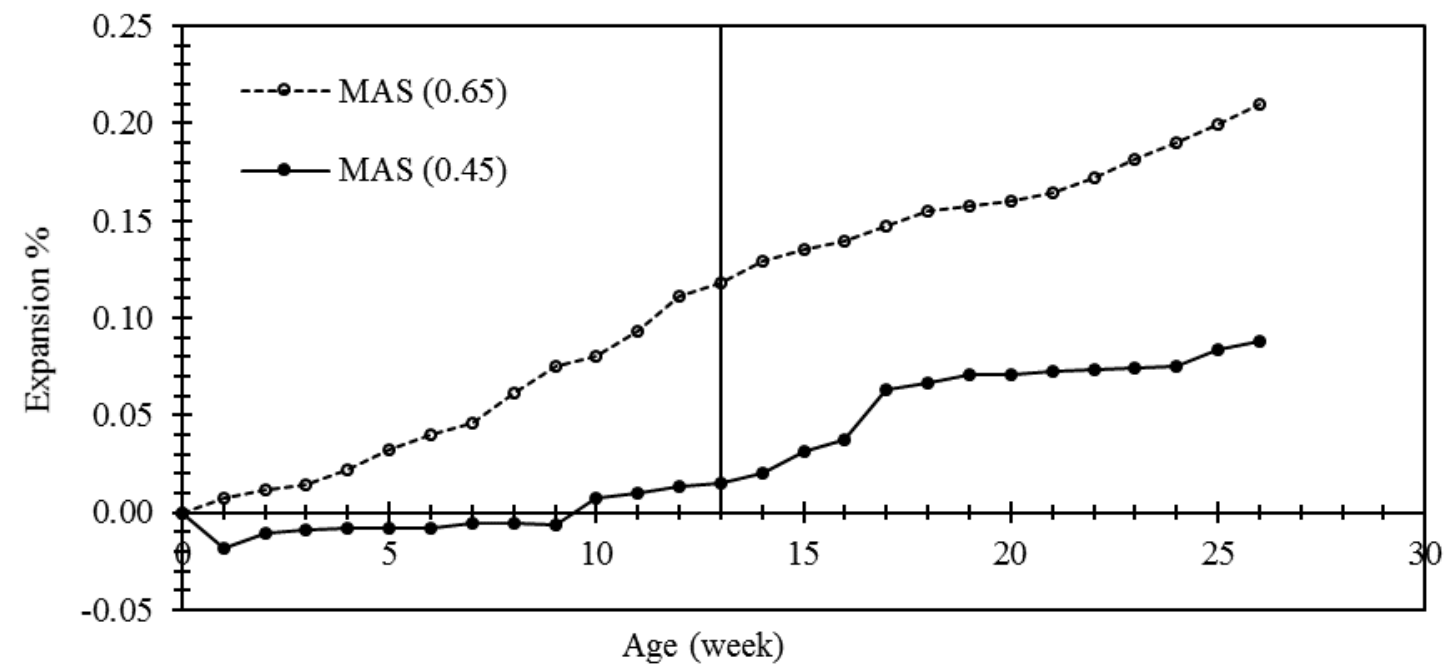

Fig. 5. The expansion in mortar bar samples made with MAS aggregate and different w/c.

\subsubsection{Expansion testing using a soaking period of 24 hours}

In this part of the study, the same three aggregates (MAS, C1, and P) and the GU-PC were used, but only two types/levels of SCMs were examined: GU-FA and GU-MK. The mortar bars were subjected to the same testing condition as per the adopted test method [17], except that the soaking period was extended to 24 hours during both 13 -week stages of the test. This was carried out to investigate the expansion when the sodium hypochlorite penetrates the whole cross section of the samples with SCMs. As shown in Fig. 3, the solution penetrated most of the cross section of the samples without SCMs in 3 hours, but samples with SCMs required a longer time (almost 24 hours) 
to reach a similar condition. This was carried out in order to evaluate the effect of SCMs on reducing the damage beyond their ability to reduce the penetration of the oxidizing agent.

Figs. $6 \mathrm{a}$ and $6 \mathrm{~b}$ show that the expansion of the MAS mortar bars with GU-PC was much lower when the bars were soaked for 24 hours instead of 3 hours. Possible reasons for this are discussed in the discussion section. The expansion of the samples containing metakaolin showed a much different trend. There was no expansion in the first 13 weeks. However, severe expansion occurred in the second 13 weeks, as shown in Fig. 6d. The expansion took place in samples with all aggregates, including $\mathrm{P}$ and $\mathrm{C} 1$, which have no iron sulphide phases. This indicates that the expansion is not related to the oxidation of iron sulphide.
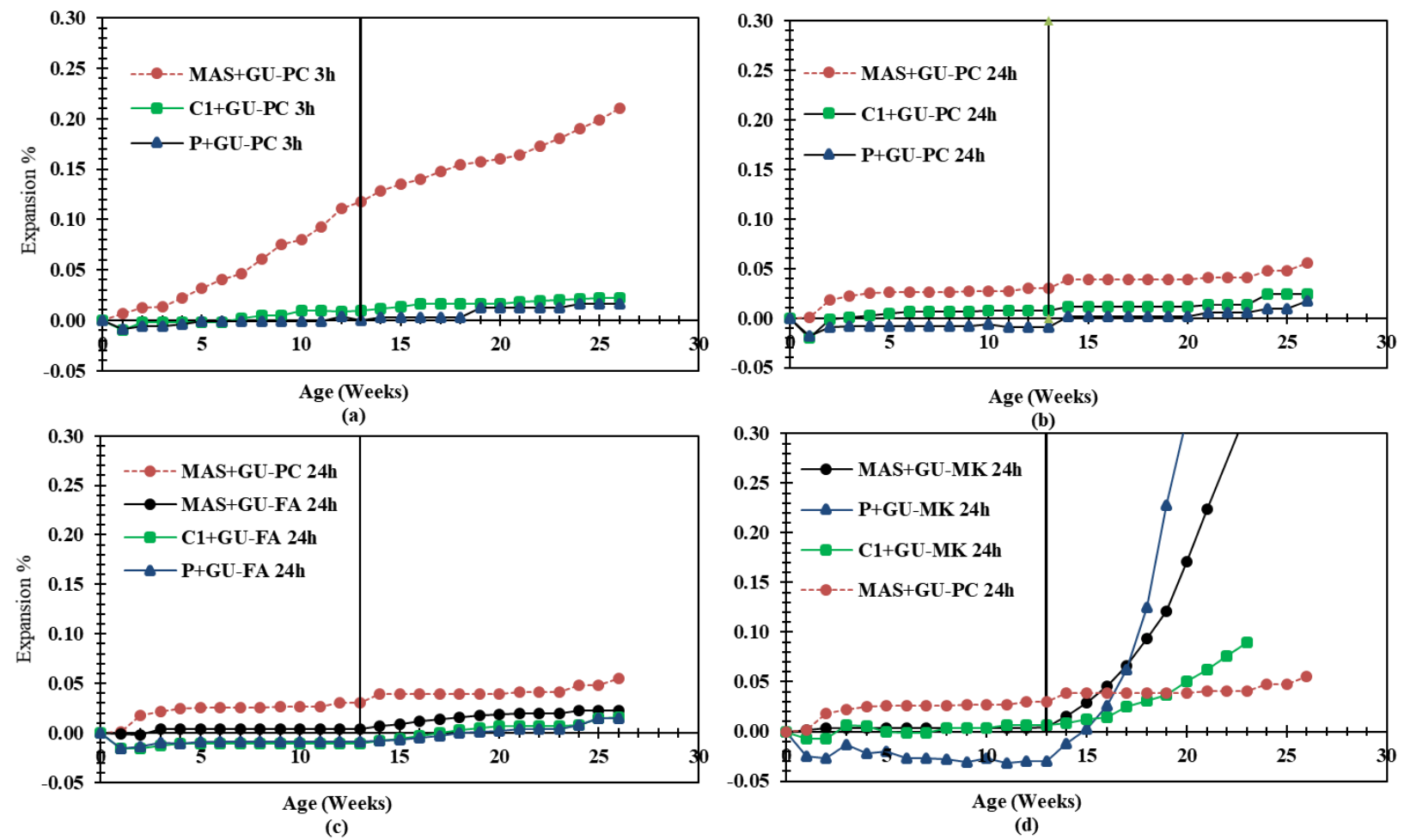

Fig. 6. Expansions of mortar bars containing P, MAS and C1 aggregates cast with (a) GU-PC soaked for 3 hours, (b) GU-PC soaked for 24 hours, (c) GU-FA soaked for 24 hours, and (d) GUMK soaked for 24 hours in $6 \% \mathrm{NaClO}$ solution. Vertical line represents moving the samples from $80^{\circ} \mathrm{C}$ to $5^{\circ} \mathrm{C}$. 


\subsubsection{Microstructural characterization}

Microstructure examination was carried out using SEM and EDS. The examination focused on samples with MK to understand the mechanisms that led to the significant expansion obtained in samples soaked for 24 hours. Fig. 7 illustrates the damage in the paste of mortar bars with the iron sulphide-bearing aggregate MAS cast with GU-MK and tested using a soaking period of 3 hours, where both ettringite and Friedel's salts were detected. It is believed that the MK contributed to the formation of Friedel's salt, as will be discussed later.

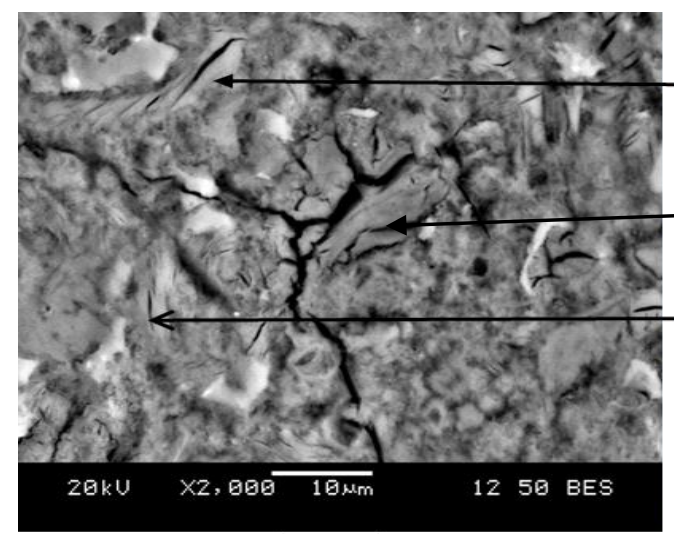

(a)

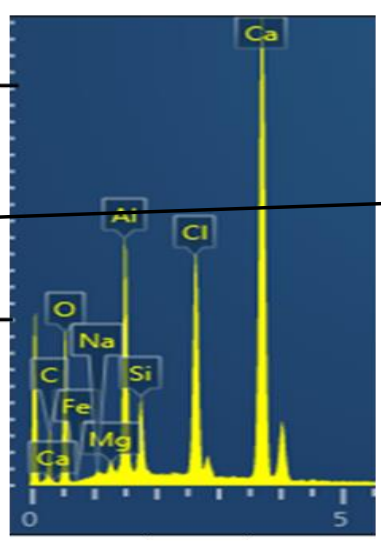

(b)

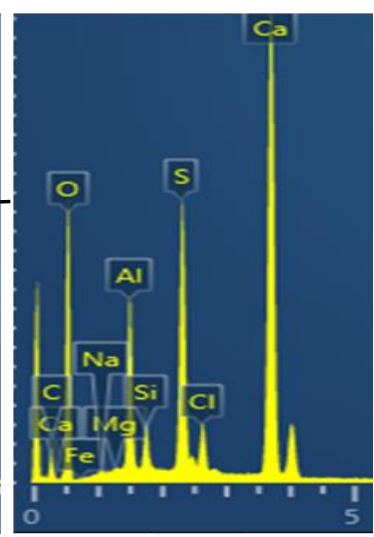

(c)

Fig.7. (a) Deteriorated paste of a mortar bar with MAS aggregate and GU-MK showing: (b) presence of Friedel's salt; (c) presence of ettringite. The test was performed with a soaking period of 3 hours. The BSE image and spectra were obtained by SEM-EDS, respectively.

Fig. 8 shows BSE images of mortar bar samples containing GU-MK and MAS aggregate tested using a soaking period of 24 hours demonstrating the presence of Friedel's salt and evidences of ettringite. The mortar bars produced no expansion in the first 13 weeks followed by severe expansion in the second 13 weeks, as presented in Fig. 6d. It should be noted that the 
microstructure examination that took place in this research did not quantify the amount of Friedel's salt or ettringite.

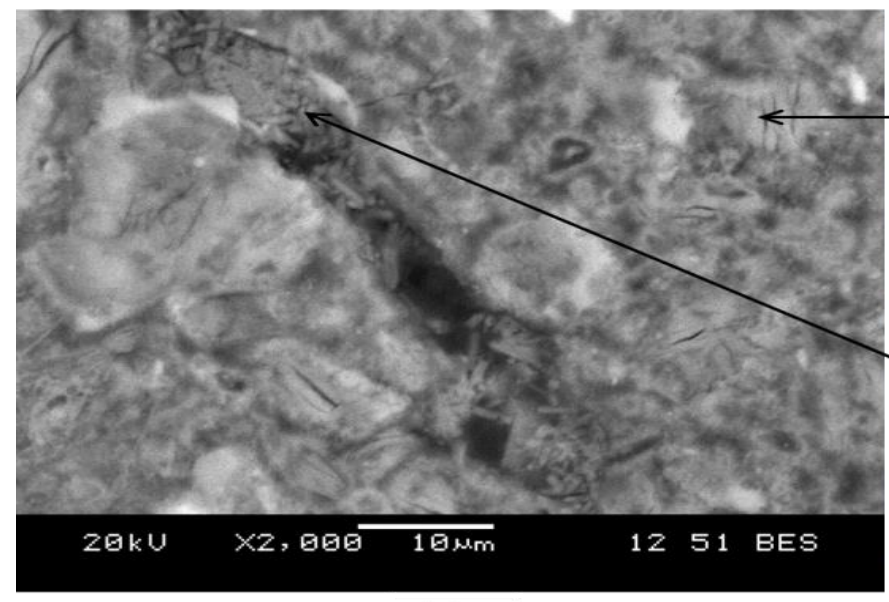

(a)

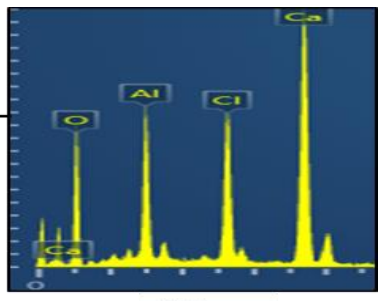

(b)

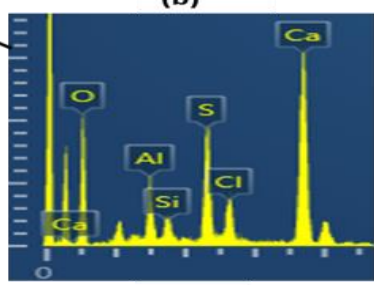

(c)

Fig. 8. (a) Damage in a mortar bar with MAS aggregate and GU-MK showing:

(b) presence of Friedel's salt (c) presence of ettringite. The samples were soaked in solution for 24 hours. The image and spectra were obtained by SEM-EDS, respectively.

\subsection{Paste Study}

The paste study was carried out to help to identify the phases developed in the cementing systems with different SCMs under extended exposure to $100 \% \mathrm{RH}$ and low temperature. This was thought to assist in determining the possible mechanism behind the obtained expansions. The paste samples were analyzed using SEM, DTA, and XRD analysis. 


\subsubsection{Microstructure study}

Fig. 9 shows the presence of Friedel's salt in the sample with GU-MK. The salt was found in air voids (image on the right) as well as within the paste matrix (image on the left) as the figure shows. For the sample with GU-FA, there was some evidence of Friedel's salt; however, it was not abundantly available. The same can be said about the sample with GU-PC.
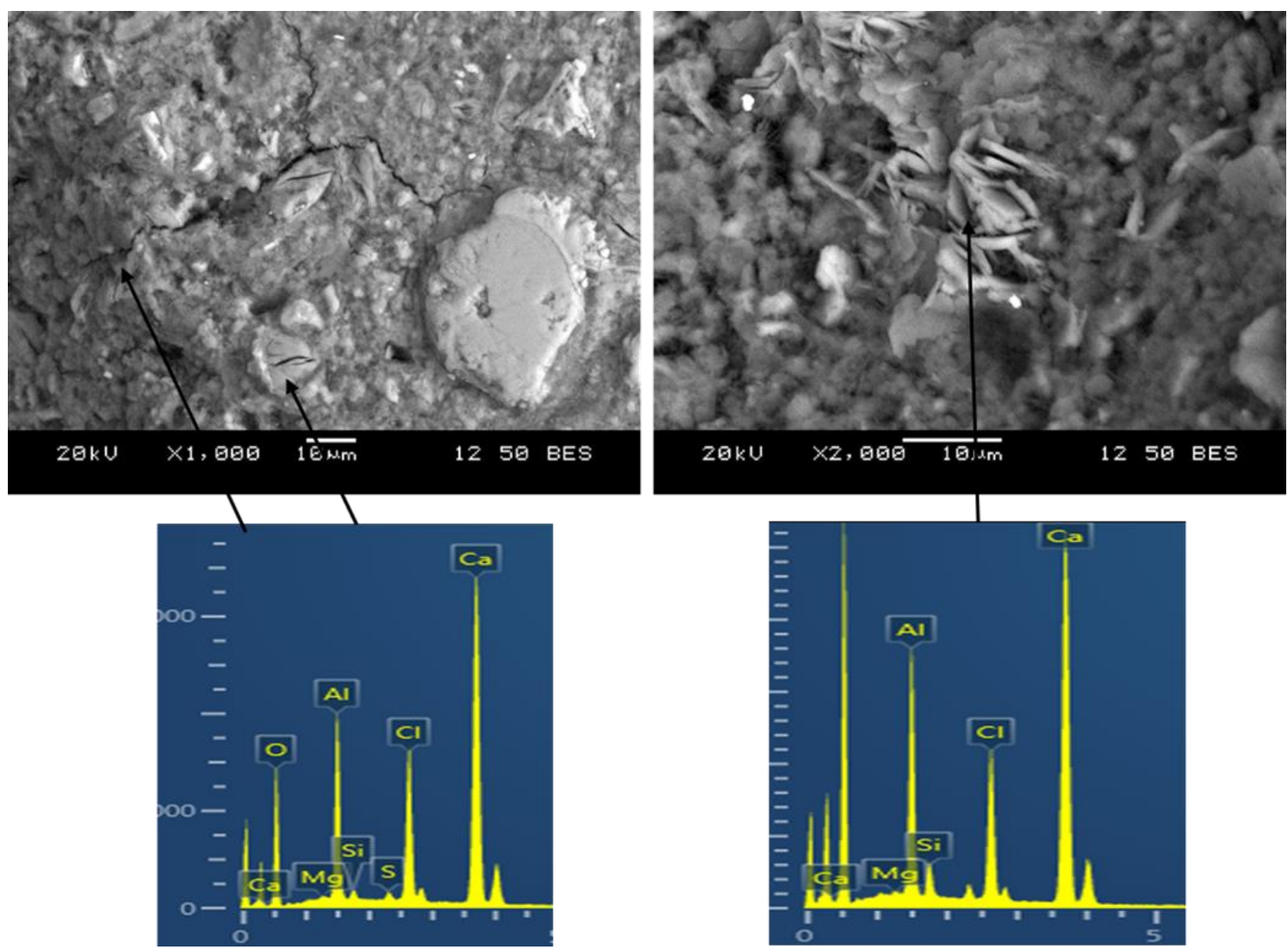

Fig. 9. Friedel's salt formation in a large area in cement paste sample containing GU-MK exposed for 24 hours to sodium hypochlorite solution. The BSE image and spectra were obtained by SEM-EDS, respectively. 


\subsubsection{Thermal Analysis}

DTA was carried out on samples cast with GU-PC, GU-FA and GU-MK. The results are shown in Fig. 10. The endotherm peaks at a temperature of about $130^{\circ} \mathrm{C}$ and between $180^{\circ} \mathrm{C}$ and $190^{\circ} \mathrm{C}$ in the three samples could be due to the presence of C-S-H and ettringite, respectively [20, 21]. The same two peaks can also be attributable to calcium aluminate hydrate $\left(\mathrm{C}_{4} \mathrm{AH}_{13}\right)$ or monosulphoaluminate [22], as both materials have the same peaks. It is clear that the same two peaks are much higher in the samples with GU-MK suggesting that this sample has higher amounts of one or a combination of the ettringite, monosulphoaluminate or calcium aluminate hydrate phases.

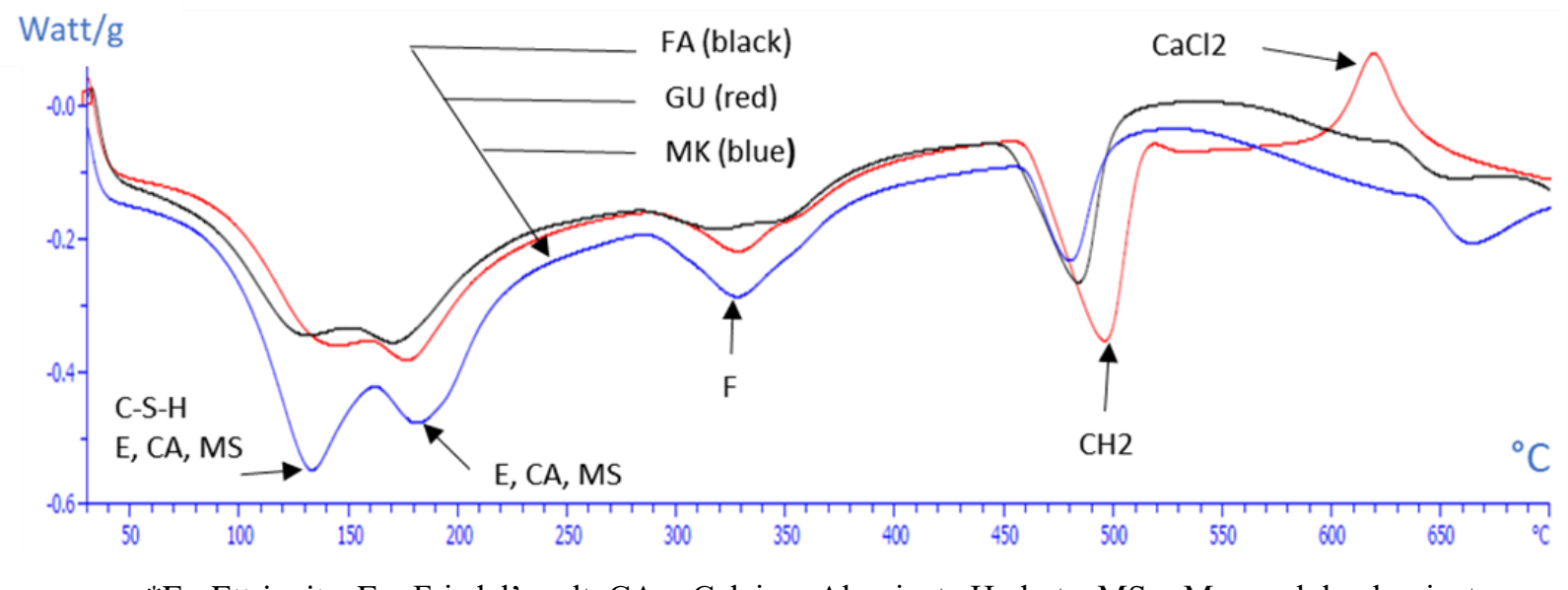

Fig. 10. DTA for the three cement paste samples cast with GU-PC, GU-FA and GU-MK.

It is also noticeable that the samples with GU-PC, GU-FA and GU-MK have a peak between 310$385^{\circ} \mathrm{C}$, which is attributable to Friedel's salt [23]. This peak is larger in the sample with GU-MK 
confirming the findings from SEM carried out on mortar bars with GU-MK. Friedel's salt can form from $\mathrm{C}_{4} \mathrm{AH}_{13}$ [24] or from monosulphoaluminate [25] in the presence of chloride ions. Hence, the $\mathrm{C}_{4} \mathrm{AH}_{13}$ or monosulphoaluminate detected in the paste sample with GU-MK has the potential of transforming to Friedel's salt, given enough chloride and time. The source of chloride ions would be the sodium hypochlorite as discussed earlier. The formation of Friedel's salt in the cementing system with GU-MK has been reported in the literature [26].

While the oxide composition of the FA used in this study shows the presence of alumina, the DTA peaks in Fig. 10 do not reflect the formation of an appreciable amount of $\mathrm{C}_{4} \mathrm{AH}_{13}$, monosulphoaluminate or Friedel's salt like the case with GU-MK. This is in line with the mortar bar results that did not show significant expansion when GU-FA was used. These observations could be due to the limited amount of reactive alumina or lower reactivity of alumina in FA compared to that in MK. The XRD of the raw materials Fig. 1 suggests that the alumina in the FA sample used in this study is in the form non-reactive mullite. This is in line with earlier works which showed low calcium fly ash to have most of its alumina content in a crystalline form; i.e. mullite [27, 28]. On the other hand, the MK sample was characterized by a diffused amorphous phase between 2 -theta equals $20-30^{\circ}$, suggesting the presence of alkali-soluble silica and alumina [29].

The high exothermal peak of the sample with GU-PC at $630^{\circ} \mathrm{C}$ could be attributable to calcium chloride $[24,26]$. This phase could be formed due to the reaction between calcium hydroxide as one of Portland cement products of hydration and chloride ions [30] as mentioned before, where 
the source of chlorides would be the sodium hypochlorite. The presence of this peak only in the sample without SCMs is unknown, as traces of calcium chloride were found in XRD patterns of all samples as will be presented later. Perhaps the DTA peak was not detected in the paste samples with $\mathrm{MK}$ and low-calcium fly ash due to the consumption of part of $\mathrm{Ca}(\mathrm{OH})_{2}$ during the pozzolanic reaction, reducing its availability for reacting with chloride ions. While Fig. 10 shows $\mathrm{Ca}(\mathrm{OH})_{2}$ in all samples, the amount was higher in samples without SCMs.

\subsubsection{X-Ray Diffraction}

The XRD carried out on hydrated samples being exposed to the oxidizing solution for 6 weeks as per the second stage of the oxidation mortar bar is shown in Fig. 11. The results showed the presences of aluminate-based phases including ettringite, thaumasite, monosulphoaluminate and Friedel's salt in the sample with GU-MK and evidence of the same phases in the GU-PC, but the peaks in the sample with GU-MK were stronger. Indeed, the monosulphoaluminate peak at 2theta around $31^{\circ}$ and the Friedel's salt peak at 2-theta around $12^{\circ}$ are stronger in the sample with GU-MK, followed by the sample with GU-PC and almost not present for the sample with GU-FA. The results of XRD were in line with those obtained using DTA. 

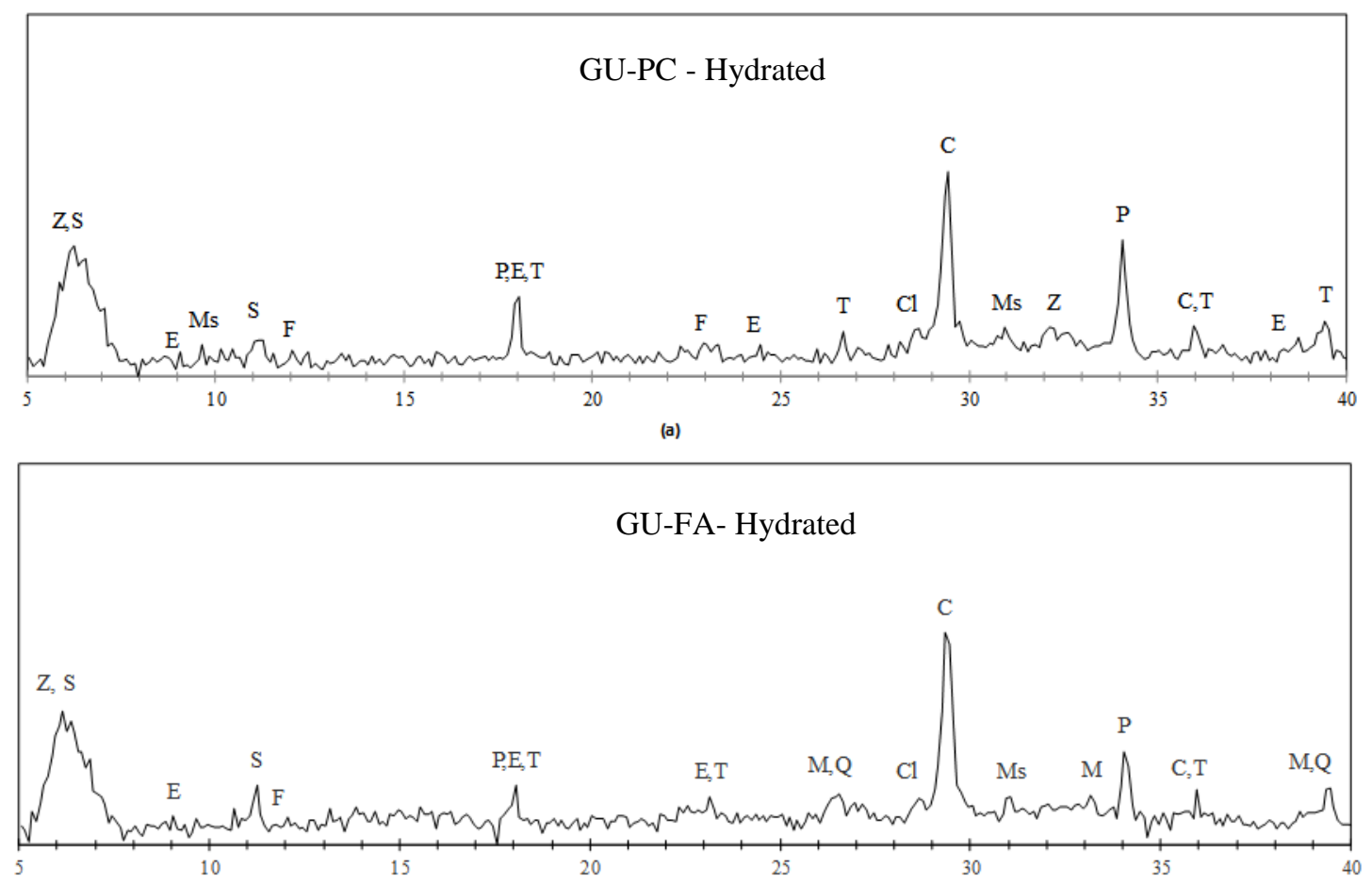

(b)

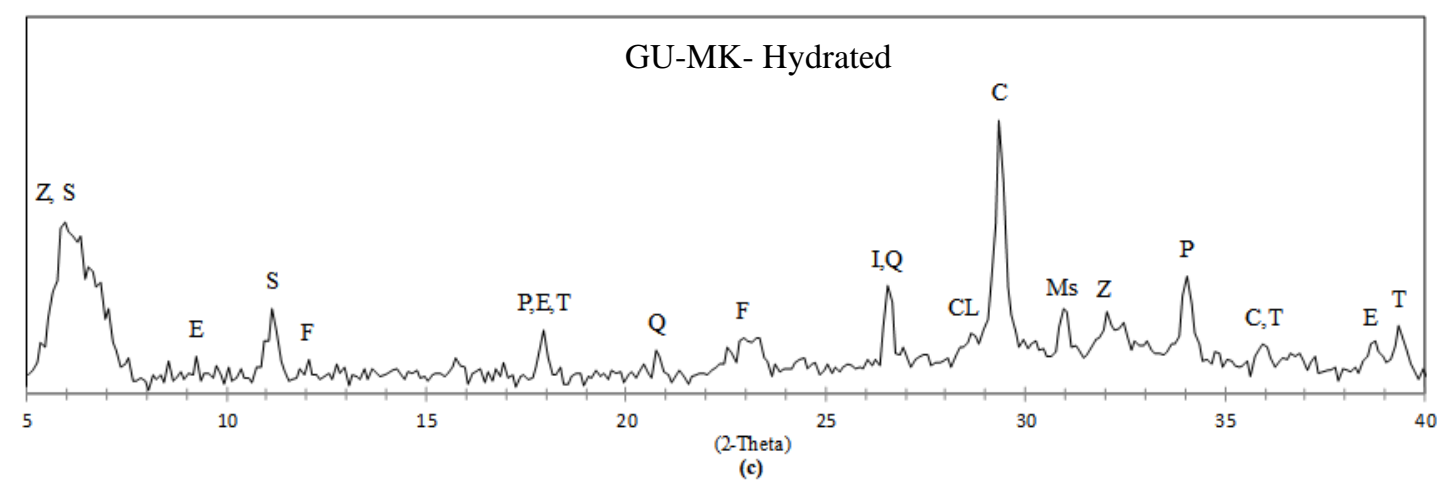

Ref. Code or Ref. from

Mineral

Ref. Code or Ref.

\begin{tabular}{|c|c|c|c|c|c|}
\hline Symbol & Mineral Name & $\underline{\text { literature }}$ & Symbol & $\underline{\text { Name }}$ & from literatur \\
\hline $\mathrm{Z}$ & Zeolite & 01-073-7924 & \multirow[t]{2}{*}{$\mathrm{Cl}$} & Calcium & \multirow[t]{2}{*}{ 00-049-1092 } \\
\hline $\mathrm{E}$ & Ettringite & 00-009-0414 & & Chloride & \\
\hline $\mathrm{F}$ & Friedel's salt & Thomas et al. [31]. & $\mathrm{T}$ & Thaumasite & 00-002-0061 \\
\hline$S$ & Silicon Oxide & 00-045-0111 & $\mathrm{C}$ & Calcite & 01-085-0849 \\
\hline Ms & Monosulphate & Lothenbach et al. [32]. & M & Mullite & 00-006-0259 \\
\hline \multirow[t]{2}{*}{$P$} & \multirow[t]{2}{*}{ Portlandite } & \multirow[t]{2}{*}{ 00-004-0733 } & Q & Quartz & 01-074-3485 \\
\hline & & & I & Illite & 00-002-0050 \\
\hline
\end{tabular}

Fig. 11. XRD patterns and pattern list of hydrated paste soaked in oxidizing solution at $5^{\circ} \mathrm{C}$. 


\section{Discussion}

When the mortar bar test was performed as per proposed method [17] in which samples were soaked in the oxidizing solution for 3 hours, all tested SCMs were able to reduce the expansion compared with the sample containing iron sulphide-bearing aggregates and GU-PC. The efficacy of SCMs in reducing the expansion is related to the reduced volume of oxidizing solution absorbed by the sample or diffused through it as shown in Fig. 2 and 3, resulting in reduced oxidation.

The reduced expansion of the samples with LH-PC is not attributable to a more refined pore structure as both types of cement produced a similar mass gain and ion penetration when soaked in the testing solution as suggested by the results in Fig. 2 and Fig. 3. It is likely that the limited amount of $\mathrm{C}_{3} \mathrm{~A}$ has reduced the formation of ettringite and thaumasite, or both. It should be noted that while the second stage of the test focuses mainly on promoting thaumasite formation, ettringite can also form at $5^{\circ} \mathrm{C}$ [33]. The reduced expansion in bars with LH-PC could be due to the lower formation of ettringite and its associated expansive force.

Running the proposed mortar bar test with a soaking period of 24 hours instead of 3 hours produced much lower expansions for all aggregates tested with all cementing systems except for GU-MK. It should be noted that the trend of obtaining lower expansion when testing using a longer soaking period has been confirmed by repeating the tests on samples with fly ash and samples without SCMs. In the case of samples with MK, high expansions when testing with a soaking period of 24 hours were found for all aggregates, even for $\mathrm{C} 1$ and $\mathrm{P}$, which contain no sulphide minerals. It should be noted that MK did not show the same trend when tested for a soaking period of 3 hours. 
Similarly, cementing systems other than that with MK did not show significant expansion when tested by soaking for 24 hours. The lower expansion of samples with MAS and all cementing blends, except MK, when tested using a soaking period of 24 hours could be attributed to the shorter testing period at $80 \% \mathrm{RH}$ and $80^{\circ} \mathrm{C}$ ( 2 days instead of 3). Perhaps a longer time under this condition is essential for oxidation to proceed. It is evident that high expansion, when testing using a 24-hour soaking period, occurred only in a system containing a considerable amount of alumina, such as MK. It should be noted that the expansion occurred in the second 13 weeks of the test, where samples were all the time at $\mathrm{RH}$ of $100 \%$, either through soaking in for 24 hours at room temperature or stored at $5^{\circ} \mathrm{C}$ above water.

Examining paste samples using SEM, DTA, and XRD showed the presence of Friedel's salt and ettringite, monosulphoaluminate and calcium aluminate hydrates in excessive amounts in the sample with MK. The formation of Friedel's salt in the presence of MK is thought to be due to the extended period of exposure of the sample to chloride ions produced from the sodium hypochlorite when soaked for 1 day, rather than 3 hours as originally proposed in the test method [17, 18]. This high volume of chloride reacts with high aluminate phases formed due to the presence of reactive alumina from MK to form Friedel's salt.

Initially, the chloride ions become available from the sodium hypochlorite solution following these reactions [30, 34]:

$$
\begin{aligned}
& \mathrm{NaClO}+\mathrm{H}_{2} \mathrm{O} \rightarrow \mathrm{HOCl} \text { (hypochlorous acid) }+\mathrm{NaOH} \text { (sodium hydroxide) } \\
& 2 \mathrm{HOCl} \text { (hypochlorous acid) } \rightarrow 2 \mathrm{HCl} \text { (hydrochloric acid) }+\mathrm{O}_{2}
\end{aligned}
$$


$2 \mathrm{HCl}$ (hydrochloric acid) $+\mathrm{Ca}(\mathrm{OH})_{2} \rightarrow \mathrm{CaCl}_{2}+2 \mathrm{H}_{2} \mathrm{O}$

When sodium hypochlorite is mixed with water, the reaction produces hypochlorous acid and sodium hydroxide [34]. The hypochlorous acid is then converted to hydrochloric acid and oxygen [34]; the hydrochloric acid reacts with calcium hydroxide as one of the hydrated Portland cement products to form calcium chloride and water [30]. In the case of cementing systems with high alumina content, such as cementing blend with MK, the sulphur to alumina ratio is relatively low, which favors the formation of monosulphoaluminate rather than ettringite during hydration. In such systems, calcium aluminate hydrates also form. In the presence of $\mathrm{CaCl}_{2}$, Friedel's salt can form following the equations:

From calcium aluminate hydrate:

$$
\mathrm{C}_{3} \mathrm{~A} \cdot \mathrm{Ca}(\mathrm{OH})_{2} \cdot 12 \mathrm{H}_{2} \mathrm{O}+\mathrm{CaCl}_{2} \rightarrow \mathrm{C}_{3} \mathrm{~A} \cdot \mathrm{CaCl}_{2} \cdot 10 \mathrm{H}_{2} \mathrm{O}+\mathrm{Ca}(\mathrm{OH})_{2}+\mathrm{H}_{2} \mathrm{O} \text { [35] }
$$

Or, from monosulphoaluminate:

$$
\mathrm{C}_{3} \mathrm{~A} \cdot \mathrm{CaSO}_{4} \cdot 12 \mathrm{H}_{2} \mathrm{O}+\mathrm{CaCl}_{2} \rightarrow \mathrm{C}_{3} \mathrm{~A} \cdot \mathrm{CaCl}_{2} \cdot 10 \mathrm{H}_{2} \mathrm{O}+\mathrm{CaSO}_{4} \cdot 2 \mathrm{H}_{2} \mathrm{O} \text { [35] }
$$

While Friedel's salt is not reported in the literature to cause expansion, its formation from monosulphoaluminate causes the release of sulphate as shown in equation (13). The produced sulphate ions can react with the abundantly available monosulphoaluminate forming ettringite [36]. It should be stated that ettringite was found to be stable at the moderate level of chloride, so it could have formed in the presence of chloride ions [37]. Hence, the obtained expansion in samples with MK when soaked for 24 hours could be attributed to internal sulphate attack, where the sulphate would be released from the abundantly available monosulphoaluminate during the 
formation of Friedel's salt. The DTA and XRD results suggested that the sample with MK has more Friedel's salt and possibly monosulphoaluminate, calcium aluminate hydrates, and ettringite compared with the other samples. Alternatively, the excessive amount of Friedel's salt could have caused swelling of the cementing system. However, this needs further investigation.

The significance of the results obtained here in relation to actual in-field concrete needs to be evaluated. It can be argued that the way SCMs reduce the amount or availability of an oxidizing agent in the mortar bar samples would be similar to the availability of oxygen to concrete under

field conditions. In other words, the more refined pore structure would reduce the availability of oxygen under field conditions. However, this needs validation through in-situ testing of concrete. Until then, the use of the oxidizing mortar bar test to evaluate SCMs should be treated with caution.

\section{Conclusions}

For the materials tested in this paper, the following conclusions are drawn:

1. The oxidation mortar bar test showed differences in expansions between samples with different cementing blends.

2. When the mortar bar test was run for 3 hours of soaking in oxidizing solution, the SCMs investigated here (25\% fly ash, 30\% slag, $8 \%$ silica fume, and 10\% metakaolin) and LH-PC were able to reduce the expansion in mortar bars containing iron sulphide-bearing aggregates by $50 \%$ to $85 \%$. The main suggested mechanisms behind this finding are the more refined 
pore structure of samples with SCMs and the reduced $\mathrm{C}_{3} \mathrm{~A}$ in samples with LH-PC. The relation of this to reducing oxygen penetration under field exposure needs to be examined.

3. Extending the 3-hour soaking period specified in the test to 24 hours was found to produce unreliable results as reactions other than oxidation of sulphide phases take place.

4. The results obtained here using the mortar bar test need to be validated using in-situ concrete with sulphide-bearing aggregates and SCMs.

5. Soaking the samples in sodium hypochlorite can produce Friedel's salt; however, the amount is not large enough if the soaking period is only 3 hours and no additional form of alumina is provided.

\section{Acknowledgments}

Funding of this research work was provided by a grant from the Natural Science and Engineering Research Council of Canada (NSERC) and the Ministry of Transportation, Ontario (MTO). Opinions expressed in this paper are those of the authors and may not necessarily reflect the views and policies of MTO.

\section{References}

[1] J. Berard, R. Roux and M. Durand, "Performance of concrete containing a variety of black shale," Canadian Journal of Civil Engineering, vol. 2, pp. 58-65, 1974. 
[2] R. E. Oberholster and J. E. Kruger, "Investigation of alkali-reactive, sulphide-bearing and by-product aggregates," Bulletin of Engineering Geology and the Environment, vol. 30, pp. 273-277, 1984.

[3] A. Lugg and D. Probert, "Mundic-type problems: a building material catastrophe," Construction and Building Materials, vol. 10, no. 6, pp. 467-474, 1996.

[4] T. Schmidt, A. Leemann, E. Gallucci and K. Scrivener, "Physical and microstructural aspects of iron sulfide degradation in concrete," Cement and Construction Research, vol. 41, no. 3, pp. 263-269, 2011.

[5] N. Belzile, Y. W. Chen, M. F. Cai and Y. Li, "A review on pyrrhotite oxidation," Journal of Geochemical Exploration, vol. 84, pp. 65-76, 2004.

[6] H. F. Steger, "Oxidation of sulphide minerals VII. Effect, of temperature and relative humidity on the oxidation of pyrrhotite," Chemical Geology, vol. 35, pp. 281-295, 1982.

[7] A. Shayan, "Deterioration of a concrete surface due to the oxidation of pyrite contained in pyritic aggregates," Cement and Concrete Research, vol. 18, pp. 723-730, 1988.

[8] G. S. Araujo, S. Chinchon and A. Aguado, "Evaluation of the behaviour of concrete gravity dams suffering from internal sulphate attack," IBRACON Structures and Materials Journal, vol. 1, pp. 84-112, 2008.

[9] J. Bensted, "Thaumasite - background and nature in deterioration of cements, mortars, and concretes.," Cement \& Concrete Composites, vol. 21, no. 2, p. 117-121, 1999.

[10] S. Diamond, "Thaumasite in cementitious materials," Cement and Concrete Composites, vol. 25, pp. 805-807, 2003. 
[11] N. J. Crammond, "The thaumasite form of sulfate attack in the UK," Cement and Concrete Composites, vol. 25, no. 8, pp. 809-818, 2003.

[12] J. Bensted, "Thaumasite - direct, woodfordite and other possible formation routes," Cement \& Concrete Composites , vol. 25, no. 8, pp. 873-877, 2003.

[13] S. J. Barnett, D. E. Macphee and N. J. Crammond, "Extent of immiscibility in the ettringitethaumasite system," Cement and Concrete Composites, vol. 25, no. 8, pp. 851-855, 2003.

[14] A. M. Ramezanianpour and R. D. Hooton, "Thaumasite sulphate attack in Portland and Portland-limestone cement mortars exposed to sulphate solution," Construction and Building Materials, vol. 40, pp. 162-173, 2013.

[15] A. Rodrigues, J. Duchesne and B. Fournier, "Damage evaluation of two different concrete mix designs containing sulfide-bearing aggregates," in 36th International Conference on Cement Microscopy, Milan, Italy, 2014.

[16] A. Rodrigues, J. Duchesne and B. Fournier, "Petrographic characterization of the deterioration products of a concrete containing sulfide bearing aggregates; a particular case of internal sulphate attack," in 35th International Conference on Cement Microscopy, Chicago, USA, 2013.

[17] A. Rodrigues, J. Duchesne and B. Fournier, "A new accelerated mortar bar test to assess the potential deleterious effect of sulfide-bearing aggregate in concrete," Cement and Concrete Research, vol. 73, pp. 96-110, 2015. 
[18] A. Rodrigues, J. Duchesne, B. Fournier, B. Durand, M. Shehata and P. Rivard, "Evaluation Protocol for Concrete Aggregates Containing Iron Sulfide Minerals," ACI Materials Journal, vol. 113 , no. 3 , pp. 349-359, 2016.

[19] Canadian Standards Association (CSA), A23.2-25A - A test method for detection of alkalisilica reactive aggregate by accelerated expansion of mortar bars, CSA, 2014, pp. A23.225A.

[20] J. I. Bhatty, "A Review of the Application of Thermal Analysis to Cement Admixture Systems," Thermochimica Acta, vol. 189, pp. 313-350, 1991.

[21] W. Sha, E. A. O'Neill and Z. Guo, "Differential scanning calorimetry study of ordinary Portland cement," Cement and Concrete Research, vol. 29, no. 9, pp. 1487-1489, 1999.

[22] H. W. Taylor, Cement Chemistry, 2nd ed., London: Thomas Telford Publishing, 1997.

[23] N. Saikia, S. Kato and T. Kojima, "Thermogravimetric investigation on the chloride binding behaviour of MK-lime paste," Thermochimica Acta, vol. 444, no. 1, pp. 16-25, 2006.

[24] A. K. Suryavanshi, J. D. Scantlebury and S. B. Lyon, "Mechanism of Friedel's salt formation in cements rich in tri-calcium aluminate," Cement and Concrete Research, vol. 26, no. 5, pp. 717-727, 1996.

[25] Y. Farnam, T. Washington and J. Weiss, "The Influence of Calcium Chloride Salt Solution on the Transport Properties of Cementitious Materials," Advances in Civil Engineering, vol. 2015, article ID 929864. 
[26] N. J. Coleman and C. L. Page, " Aspects of the pore solution chemistry of hydrated cement pastes containing metakaolin," Cement and Concrete Research, vol. 27, no. 1, pp. 147-154, 1997.

[27] M. H. Shehata, Effect of fly ash and silica fume on the alkali-silica reaction in concrete, University of Toronto: Ph.D. Thesis, 2001.

[28] S. Diamond and F. Lopez-Flores, "On the Distinction in Physical and Chemical Characteristics Between Lignite and Bituminous Fly Ash: In Effects of Fly Ash Incorporation in Cement and Conc," Proceedings of the MRS Symposium, Materials Research Society, pp. 34-44, 1981.

[29] C. Hea, B. Osbzckb and E. Makovicky, "Pozzolanic reaction of six principal clay minerals: activation, reactivity assessments and technological effects," Cement and Concrete Research, vol. 25, no. 8, pp. 1691-1702, 1995.

[30] A. Allahverdi and F. Skvara, "Acidic Corrosion of Hydrated Cement Based Materials, Part 1: Mechanism of the Phenomenon," Ceramics-Silikaty, vol. 44, no. 3, pp. 114-120, 2000.

[31] M. A. Thomas, R. D. Hooton, A. Scott and H. Zibara, "The effect of supplementary cementitious materials on chloride binding in hardened cement paste," Cement and Concrete Research, vol. 42, no. 1, pp. 1-7, 2012.

[32] B. Lothenbach, G. L. Saout, E. Gallucci and K. Scrivener, "Influence of limestone on the hydration of Portland cements," Cement and Concrete Research., vol. 38, p. 848-860, 2008.

[33] F. Glasser, Ettringitte Revisited, Research Seminar, University of Aberdeen, Scotland UK, http://www.caer.uky.edu/podcast/Glasser-CAERseminiar2009.pdf 
[34] B. Lenntech, "Water Trearment Soluion," Delft, Netherland., http://www.lenntech.com/processes/disinfection/chemical/disinfectants-sodium hypochlorite.

[35] K. Weslaw, Cement and Concrete Chemistry, ISBN: 978-94-007-7945-7.

[36] M. A. Florea and H. H. Brouwers, "Chloride binding related to hydration products, Part I: Ordinary Portland Cement," Cement and Concrete Research, vol. 42, pp. 282-290, 2012.

[37] S. O. Ekolu, M. A. Thomas and R. D. Hooton, "Pessimum effect of externally applied chlorides on expansion due to delayed ettringite formation: Proposed mechanism," Cement and Concrete Research, vol. 36, no. 4, pp. 688-696, 2006. 